\title{
Esophageal Retention Following Swallowing
}

National Cancer Institute

\section{Source}

National Cancer Institute. Esophageal Retention Following Swallowing. NCI Thesaurus.

Code $C 127345$.

A finding of esophageal retention following swallowing. 